\title{
Patrimônio Cultural da Saúde: a preservação do Hospital Frei Antônio (1976-1985)
}

\section{Cultural Heritage of Health: the preservation of Frei Antonio Hospital (1976-1985)}

\begin{abstract}
Resumo:
O presente trabalho é resultado de uma dissertação de mestrado em que se analisou a trajetória de tombamento do Hospital Frei Antônio, antigo Hospital dos Lázaros do Rio de Janeiro, localizado no bairro de São Cristóvão, e sua relação com as políticas de preservação cultural desenvolvidas pela Prefeitura da Cidade do Rio de Janeiro entre 1975 e 1985. A partir da análise do processo de tombamento, pretendeu-se entender a importância histórica da assistência oferecida aos leprosos no Lazareto de São Cristóvão, que justificou o ato de salvaguarda da edificação como patrimônio cultural carioca na década de 1980. Pretendeu-se, igualmente, assinalar os resquícios materiais da saúde ainda existentes no local. Almeja-se colaborar para os estudos no âmbito da arquitetura hospitalar, história da saúde, história do Rio de Janeiro, patrimônio cultural da saúde, políticas culturais e profilaxia da lepra.
\end{abstract}

Palavras-chave: Patrimônio Cultural da Saúde, Hanseníase, Hospital Frei Antônio.

\section{Abstract: \\ The present work is the result of a master's dissertation, in which the history of the "Hospital Frei Antônio", former "Hospital dos Lázaros of Rio de Janeiro", located in the district of São}

\footnotetext{
${ }^{1}$ Mestre em Preservação e Gestão do Patrimônio Cultural das Ciências e da Saúde pela Fundação Oswaldo Cruz (FIOCRUZ). Especialista em Patrimônio Cultural pela Fundação Oswaldo Cruz (FIOCRUZ). Graduado em História pela Universidade Salgado de Oliveira (UNIVERSO). Membro do Grupo de Trabalho História e Patrimônio Cultural da Associação Nacional de História (ANPUH). Integrante do Grupo de Pesquisa Saúde e Cidade: Arquitetura, Urbanismo e Patrimônio Cultural (FIOCRUZ/CNPq/DGP). Orientador: Prof. Dr. Renato da Gama-Rosa Costa. E-mail: tarcisiomacabu@yahoo.com.br
} 


\section{Apresentação do Tema}

Cristóvão, was analyzed, as well as its relationship with the
cultural preservation policies developed by the Rio de Janeiro
City Hall, between 1975 and 1985. From the analysis of the
protection process, it was intended to understand the historical
importance of the assistance offered to lepers in the "Lazareto
of São Cristóvão", which justified the act of safeguarding the
building as a "carioca cultural heritage" in the decade of 1980. It
was also intended to point out the remnants of health material
still existing on the place. It is hoped to collaborate for studies in
the scope of hospital architecture, health history, history of Rio
de Janeiro, cultural heritage of health, cultural policies and
prophylaxis of leprosy.

Keywords: Cultural Heritage of Health, Leprosy, Frei Antonio Hospital.

Nos últimos anos, investigações relativas à preservação do patrimônio cultural vêm aumentando e chamando a atenção de historiadores, arquitetos, urbanistas, paisagistas, conservadores, geógrafos, cientistas sociais, médicos e gestores públicos, incluindo estudos que tratam da memória de instituições hospitalares e seus acervos a serem salvaguardados. Esses trabalhos contribuem para o reconhecimento, a identificação e a valorização dos bens culturais da saúde, categorizando-os como espaços de memória, pesquisa, difusão e ensino.

O Hospital Frei Antônio, administrado pela Irmandade do Santíssimo Sacramento da Candelária (ISSSC), está situado à Rua São Cristóvão, 870, no Bairro Imperial de São Cristóvão, na cidade do Rio de Janeiro/RJ. ${ }^{2}$ Limita-se ao Norte com a rua São Cristóvão, as instalações do Gasômetro (Companhia Distribuidora de Gás do Rio de Janeiro) e a Praça Mário Nazaré; a Leste, com a rua Inhomirim e os fundos dos imóveis localizados na rua Bela; ao Sul, com os pavilhões do $1^{\circ}$ Batalhão de Guardas (Batalhão do Imperador), assentados na Av. Pedro II; e a Oeste, com o restante das edificações do Gasômetro. Em sua circunvizinhança coexistem instituições governamentais e privadas, bem como, construções civis, cujo acervo arquitetônico materializa o passado aristocrático, industrial, comercial e migratório da região. O conjunto urbano é composto por palacetes neoclássicos,

\footnotetext{
2 No decorrer dos séculos, o hospital foi batizado como Hospital dos Lázaros do Rio de Janeiro, Real Hospital dos Lázaros, Imperial Hospital dos Lázaros, Lazareto de São Cristóvão e Hospital Frei Antônio.
} 
chalés românticos, sobrados ecléticos, residências em estilo normando, art déco e neocolonial, e ainda, prédios de inspiração modernista.

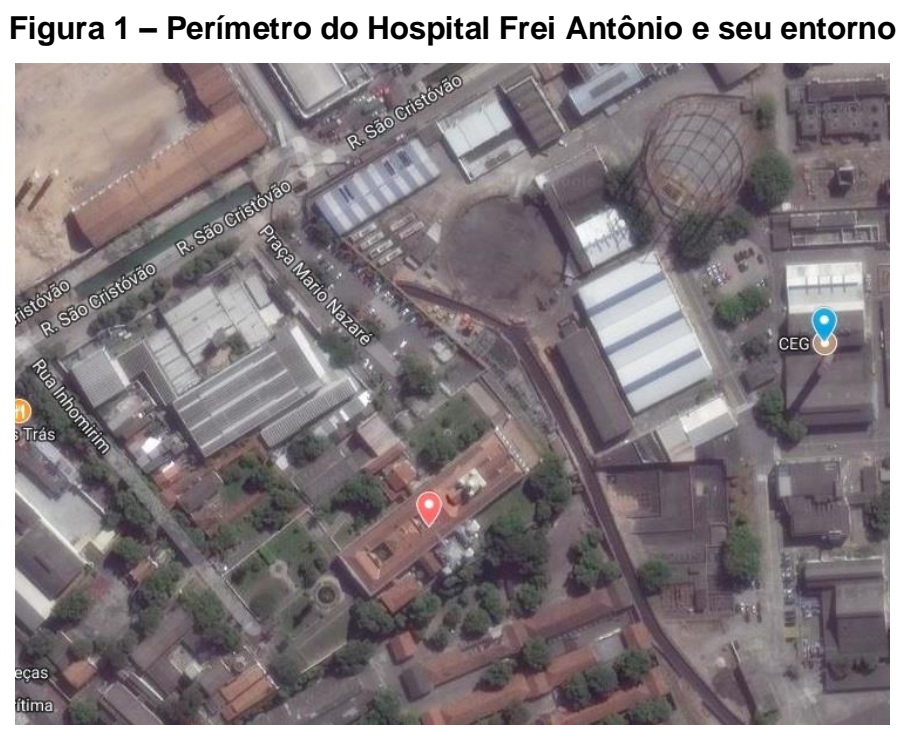

Fonte: Adaptado pelo autor (GOOGLE, 2018).

As origens do hospital remontam ao ano de 1741, quando Gomes Freire de Andrade, Conde de Bobadela, decretou o asilamento de meia centena de leprosos em precárias construções localizadas na Praia de São Cristóvão. Devido à expulsão dos jesuítas da Colônia após 1759, D. Frei Antônio do Desterro, bispo de São Sebastião do Rio de Janeiro, rogou ao novo Vice-Rei, Conde da Cunha, a remoção dos morféticos para a sede da fazenda da Companhia de Jesus, assentada nas proximidades. Em 1763, a Irmandade do Santíssimo Sacramento da Candelária se encarregou da gestão daquele Lazareto, posteriormente denominado Hospital dos Lázaros do Rio de Janeiro. Em consequência da chegada da Família Real, em 1817, o edifício foi ocupado pelos Voluntários Reais do Príncipe, visando guarnecer a Quinta da Boa Vista. Os doentes foram transferidos para a Ilha das Enxadas e a llha dos Frades, situadas na Baía de Guanabara. Em 1833, os pacientes retornaram para o antigo prédio do hospital, em São Cristóvão. Especificamente em 1941, o Hospital dos Lázaros recebeu o nome de Hospital Frei Antônio, usufruindo das políticas de saúde pública e contribuindo para as pesquisas de combate à lepra. Em 1947, as dependências do leprosário foram adaptadas para acolher o Instituto de Leprologia, órgão do Serviço Nacional de Lepra do Departamento Nacional de Saúde. Já em 1978, a 
unidade hospitalar hospedou a Divisão Nacional de Dermatologia Sanitária. No ano de 1987, idealizou-se o uso das edificações do Ministério da Saúde construídos no terreno do hospital como Lar Geriátrico, sendo que tal proposta não chegou a ser concluída. ${ }^{3}$

Em sua história, a entidade funcionou como leprosário, hospital especializado, laboratório de leprologia, centro de pesquisas, sede de órgãos sanitários e idealizado como lar geriátrico. Essas atribuições se alinhavam à justificativa isolacionista dos doentes desde sua fundação até o século $X X$. Os novos experimentos da ciência médica fariam rever a política oficial de internação compulsória no Brasil, levando ao seu gradual desuso. Compreendeu-se que tal contexto histórico, científico e assistencial validou a patrimonialização do Hospital Frei Antônio em 1985. Entretanto, o motivo determinante para o tombamento do hospital se deve ao risco da perda da visibilidade e da ambiência original, ocasionado pelas obras de melhoramentos em seu entorno e a poluição visual gerada pelo Gasômetro de São Cristóvão. ${ }^{4}$ Interpretou-se, também, que as remotas atividades assistenciais do Lazareto, poderiam fundamentar sua patrimonialização pelo Poder Público Municipal. A legitimação do passado caritativo, a salvaguarda da memória institucional e os indícios de descaracterização daquela edificação a ser tombada se vinculavam ao contexto histórico das políticas patrimoniais de meados dos anos 1970/80 no Brasil, em geral, e no Rio de Janeiro, em particular.

Figura 2 - Vista aérea do Gasômetro, em primeiro plano, e do Hospital Frei Antônio, à direita

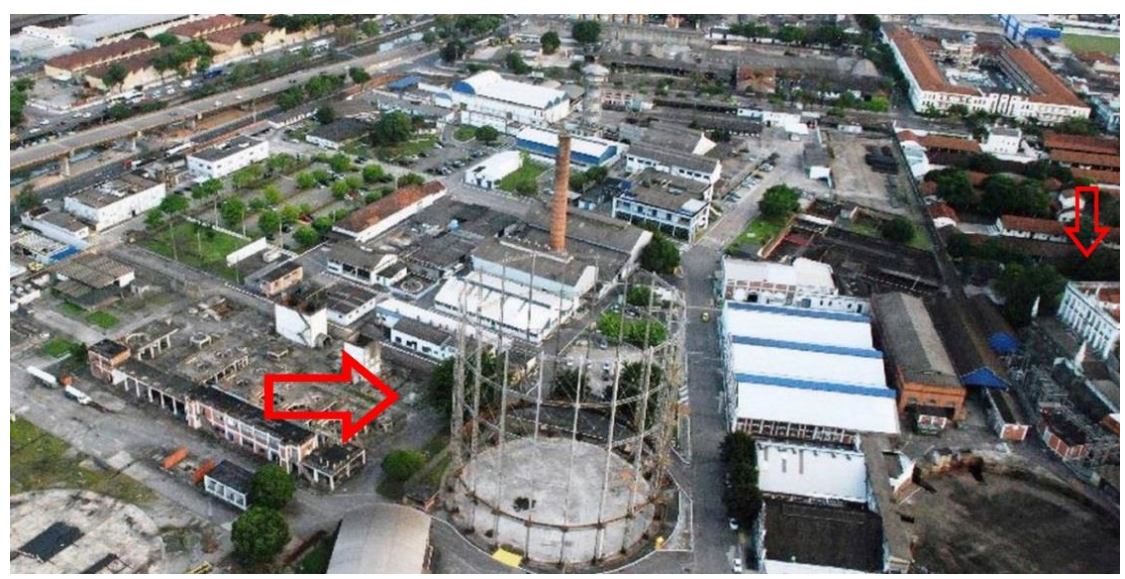

Fonte: Adaptado pelo autor (O GLOBO, 2012).

\footnotetext{
${ }^{3}$ No decorrer dos séculos, o hospital foi batizado como Hospital dos Lázaros do Rio de Janeiro, Real Hospital dos Lázaros, Imperial Hospital dos Lázaros, Lazareto de São Cristóvão e Hospital Frei Antônio.

${ }^{4}$ O Gasômetro se situa na Avenida Pedro II, 68, São Cristóvão, Rio de Janeiro/RJ.
} 
Figura 3 - Instalações do Gasômetro de São Cristóvão e o Hospital Frei Antônio, ao fundo

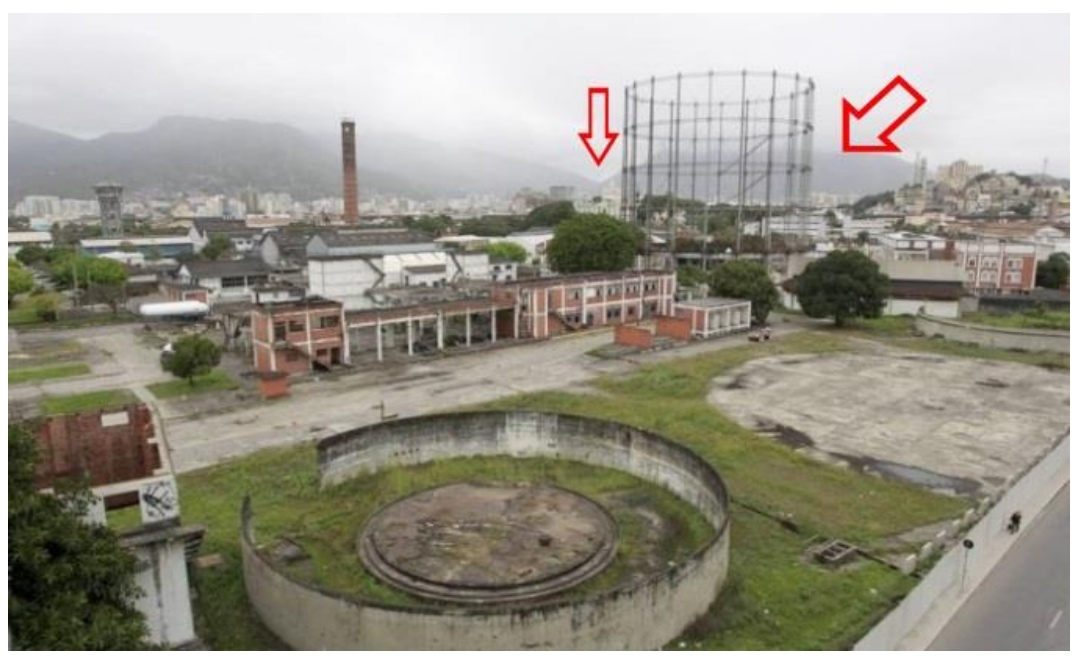

Fonte: Adaptado pelo autor (O GLOBO, 2014).

\section{Caracterização do Problema de Pesquisa}

Por meio de uma pesquisa exploratória realizada entre 2014 e 2015 no Arquivo Francisco Batista Marques Pinheiro (AFBMP), ${ }^{5}$ gerenciado pela Irmandade da Candelária, ${ }^{6}$ foram mapeados documentos históricos, arquitetônicos, cartográficos e iconográficos do Hospital Frei Antônio. Naquela circunstância, identificou-se uma documentação relativa ao tombamento do hospital datada das décadas de 1970/80. Ao examiná-la, despontaram as seguintes questões: Como decorreu o tombamento daquele hospital? Quais razões existiam para que se almejasse sua patrimonialização? Como a Prefeitura da Cidade do Rio de Janeiro operava com as políticas culturais protetivas naquele momento? A partir destas perguntas, elaborou-se um projeto de pesquisa nomeado $O$ tombamento de um patrimônio cultural da saúde: o caso do Hospital Frei Antônio que, em 2016, foi revisado para o processo seletivo do Mestrado Profissional em Preservação e Gestão do Patrimônio Cultural das Ciências e da Saúde, da Casa de Oswaldo Cruz (PPGPAT/COC/FIOCRUZ).

\footnotetext{
${ }^{5}$ Criado em 2001, o Arquivo contém manuscritos, impressos, livros, fotografias, plantas arquitetônicas, mapas, documentação administrativa e recortes de jornais. O acervo consta com aproximadamente 800 metros lineares de documentos referentes à Irmandade e à história da cidade do Rio de Janeiro.

${ }^{6}$ A Administração da ISSSC, o Arquivo Francisco Batista Marques Pinheiro e a Biblioteca Ramiz Galvão estão localizados na Avenida Rio Branco, 57, 5ำ andar, Centro, Rio de Janeiro/RJ.
} 
A problemática central do trabalho se baseou no questionamento: de que forma o tombamento do Hospital Frei Antônio, ocorrido entre 1976 a 1985, poderia contribuir para os estudos das políticas de preservação cultural no Rio de Janeiro? Este recorte temporal se refere aos anos da solicitação de tombamento (1976) e da publicação do Decreto Municipal ํo 4.926/85, que ratificou a patrimonialização do Lazareto (1985).

O objetivo geral da investigação era analisar o tombamento do Hospital Frei Antônio e sua relação com as políticas de preservação cultural da Prefeitura da Cidade do Rio de Janeiro entre 1975 e 1985. Dentre os objetivos específicos, desejou-se compreender a influência do contexto assistencial aos leprosos no Rio de Janeiro, mediante a atuação da Irmandade do Santíssimo Sacramento da Candelária da Candelária através do Lazareto de São Cristóvão; identificar, nos vestígios materiais da saúde existentes no leprosário, a conexão com a profilaxia da lepra e a salvaguarda da edificação como patrimônio cultural carioca; e por fim, examinar a trajetória do tombamento do hospital por intermédio das políticas de proteção cultural das décadas de 1970/80.

A fundamentação teórica se respaldou nas concepções de $A$ retórica da perda: os discursos do patrimônio cultural no Brasil (GONÇALVES, 2002), O patrimônio em processo: trajetória da política federal de preservação no Brasil (FONSECA, 2005), Hospital São Cristóvão dos Lázaros: entre os muros da exclusão (SANTOS, 2005), Asilos Colônias Paulistas: análise de um modelo espacial de confinamento (COSTA, 2008a), Arquitetura e Saúde no Rio de Janeiro (COSTA, 2008b), Os arquitetos da memória: sociogênese das práticas de preservação do patrimônio cultural no Brasil (CHUVA, 2009), O Estado na preservação de bens culturais: o tombamento (RABELLO, 2009), Arquitetura profilática: leprosários brasileiros (ALECRIM, 2012), Quadrilátero da Saúde: espaço de ensino, pesquisa e saúde pública em São Paulo (MIURA, 2012), Lepra, medicina e políticas de saúde no Brasil (CABRAL, 2013), O patrimônio arquitetônico da saúde: discussões sobre a história da arquitetura hospitalar do século XIX (MONTEIRO, 2014), Preservação do Patrimônio Cultural da Saúde no Brasil: uma questão emergente (SERRES, 2015) e Leprosários ao sul do Brasil: de locais de sofrimento a lugares de memória (SERRES \& BORGES, 2015).

Entre as referências bibliográficas, priorizou-se os artigos científicos, livros impressos, manuais, guias, dissertações e teses. O acesso a elas se deu por meio dos 
acervos da Biblioteca Ramiz Galvão (ISSSC), ${ }^{7}$ da Biblioteca Oswaldo Porto Rocha (AGCRJ), da Biblioteca de História das Ciências e da Saúde (COC/FIOCRUZ), da Biblioteca do Instituto Histórico e Geográfico Brasileiro (IHGB), da Biblioteca do Centro Cultural Banco do Brasil (CCBB/RJ), da Biblioteca Parque Estadual (BPE/SEC), da Biblioteca Parque de Niterói (BPN/SEC), da Biblioteca do Centro Cultural da Justiça Federal (CCJF), da Biblioteca do Museu de Arte do Rio (MAR) e em sítios eletrônicos.

O uso de fontes primárias administrativas resultantes do tombamento de uma instituição de saúde para terapêutica da hanseníase foi uma característica relevante neste trabalho. Esta documentação propiciou o surgimento de novos significados, novas narrativas e novas perspectivas no tocante às políticas de preservação cultural empreendidas pela Prefeitura da Cidade do Rio de Janeiro entre 1975 a 1985.

O objeto de estudo se insere no âmbito do Patrimônio Cultural da Saúde ${ }^{8}$ e se conecta com a historiografia da saúde pública, da assistência médica, das doenças, das instituições hospitalares, da arquitetura, do paisagismo, da urbanização e das políticas de preservação cultural, contemplando o legado assistencial, científico e estético do Hospital Frei Antônio à cidade do Rio de Janeiro.

\footnotetext{
7 Organizada em 2001, a Biblioteca Ramiz Galvão possui aproximadamente 2.370 obras. O acervo é constituído por livros e periódicos relacionados ao campo da história da arte, história do Rio de Janeiro, irmandades cariocas e Igreja da Candelária.

8 Patrimônio Cultural da Saúde é entendido como "um conjunto de bens materiais e simbólicos socialmente construídos, que expressam o processo da saúde individual e coletiva nas suas dimensões científica, histórica e cultural" (SANGLARD \& COSTA, 2008).
} 
Figura 4 - Fachada principal do Hospital Frei Antônio

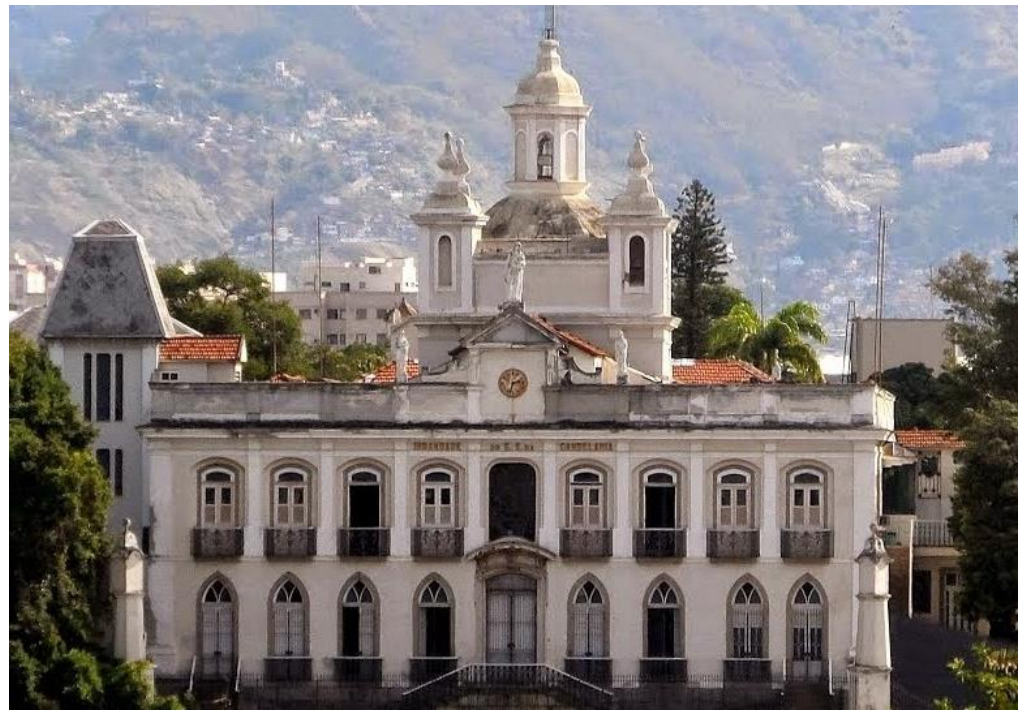

Fonte: Literatura \& Rio de Janeiro (2009).

Figura 5 - Corredor do Hospital Frei Antônio

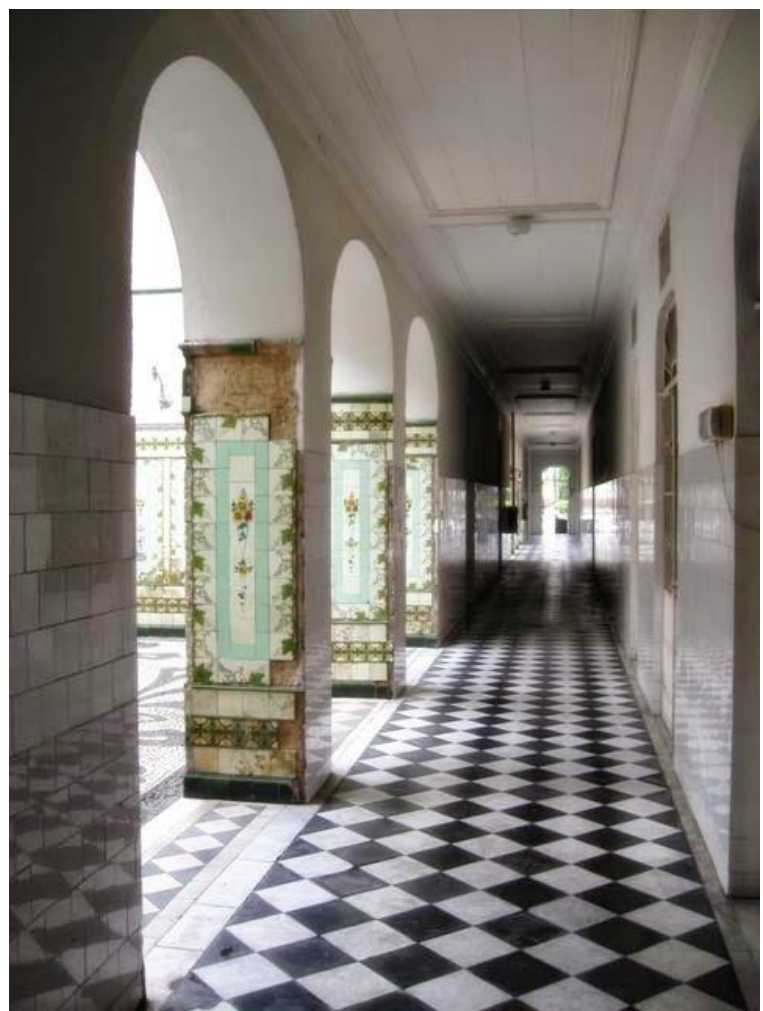

Fonte: Azulejos antigos no Rio de Janeiro (2014). 


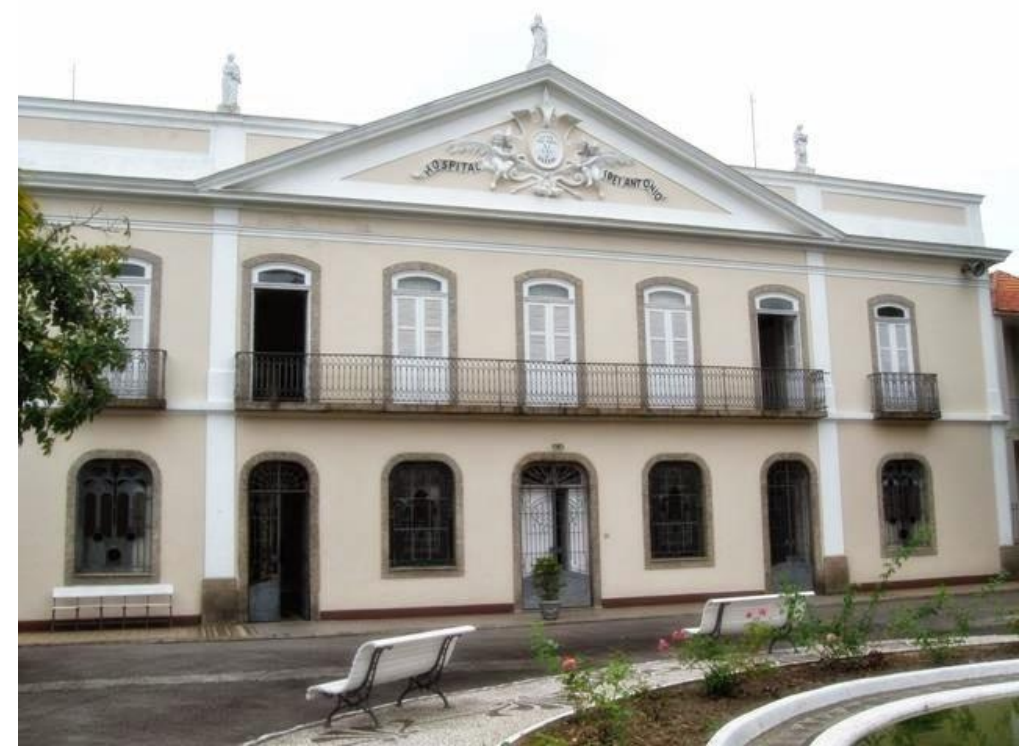

Fonte: Azulejos antigos no Rio de Janeiro (2014).

\section{Metodologia}

Os procedimentos metodológicos se concentraram em quatro fases: 1) Exploração bibliográfica, 2) Coleta de dados e análise das fontes, 3) Mapeamento de fontes complementares, 4) Analogia das referências teóricas e sistematização das informações, e 5) Escrita e revisão da dissertação (BASTOS, 2018).

$\mathrm{Na}$ primeira etapa, realizou-se a seleção, leitura e fichamento das referências bibliográficas alusivas às práticas assistenciais aos leprosos, às políticas de profilaxia da lepra, às ações de preservação cultural e às reflexões relativas à história, memória, patrimônio e saúde.

$\mathrm{Na}$ segunda etapa, efetivou-se pesquisas documentais e análises das fontes coletadas. Dentre elas, destacam-se as correspondências, os memorandos, as notificações, os ofícios, os relatórios, os pareceres, os estatutos, os regulamentos, os tratados, as fotografias, os mapas, os gráficos, as plantas arquitetônicas, as notícias de jornais e os trechos de obras de referência histórica. Tal documentação foi consultada no Arquivo Francisco Batista Marques Pinheiro (AFBMP), no Instituto Rio Patrimônio da Humanidade (IRPH), no Arquivo Geral da Cidade do Rio de Janeiro (AGCRJ), no Instituto Histórico e 
Geográfico Brasileiro (IHGB), no Departamento de Arquivo e Documentação da Casa de Oswaldo Cruz (DAD/COC) e no Arquivo Público do Estado do Rio de Janeiro (APERJ).

$\mathrm{Na}$ etapa seguinte, mapeou-se legislações federais, estaduais e municipais disponíveis nos sites do Instituto do Patrimônio Histórico e Artístico Nacional (IPHAN), do Arquivo Público do Estado do Rio de Janeiro (APERJ), da Câmara Municipal do Rio de Janeiro (CMRJ), do Senado Federal e da Câmara dos Deputados. Pesquisou-se, também, artigos jornalísticos nos sítios eletrônicos da Hemeroteca Digital da Fundação Biblioteca Nacional (FBN), do jornal O Globo e do periódico Folha de São Paulo.

$\mathrm{Na}$ quarta etapa, analisou-se os dados coletados, os levantamentos bibliográficos e as bases teóricas da investigação, visando sistematizar as informações em gráficos e tabelas.

Na última etapa, materializou-se a escrita e a revisão do texto dissertativo.

\section{Estrutura da Dissertação}

A dissertação foi dividida em 5 partes: Introdução, Capítulo I, Capítulo II, Capítulo III e Conclusão.

No Capítulo I - A assistência à Lepra no Rio de Janeiro (1915-1985) - apresentou-se o contexto de assistência aos leprosos no Rio de Janeiro a partir da atuação do Hospital dos Lázaros, posteriormente denominado Hospital Frei Antônio, mantido pela Irmandade do Santíssimo Sacramento da Candelária. Este período se refere à criação da Comissão de Profilaxia da Lepra (1915-1919) e ao tombamento efetivo do hospital pela Prefeitura da Cidade do Rio de Janeiro (1985). O propósito deste capítulo foi realizar um breve panorama histórico das políticas de profilaxia da lepra estabelecidas na Capital Federal e das práticas assistenciais aos morféticos no Lazareto de São Cristóvão.

No Capítulo II - Os aspectos arquitetônicos e urbanísticos do Hospital dos Lázaros / Hospital Frei Antônio - tratou-se das transformações urbanas do bairro de São Cristóvão e das intervenções arquitetônicas realizadas no leprosário no transcorrer de sua história. Identificou-se na arquitetura hospitalar, os resquícios materiais relacionados à saúde e ao tratamento da hanseníase, que contribuíram para sua patrimonialização em 1985.

No Capítulo III - O tombamento do Hospital Frei Antônio (1976-1985) - analisou-se o trâmite burocrático do tombamento do Lazareto, desde a solicitação inicial, em 1976, à 
publicação do Decreto Municipal no 4.926/85, em 1985, correlacionando-o às políticas de preservação cultural da época. Mencionou-se, também, as ações de patrimonialização desenvolvidas pela Prefeitura da Cidade do Rio de Janeiro no decorrer dos anos 1980. Além disso, abordou-se os riscos, os desafios e as possibilidades atuais para se preservar o Hospital Frei Antônio em razão das transformações urbanas no bairro de São Cristóvão e adjacências.

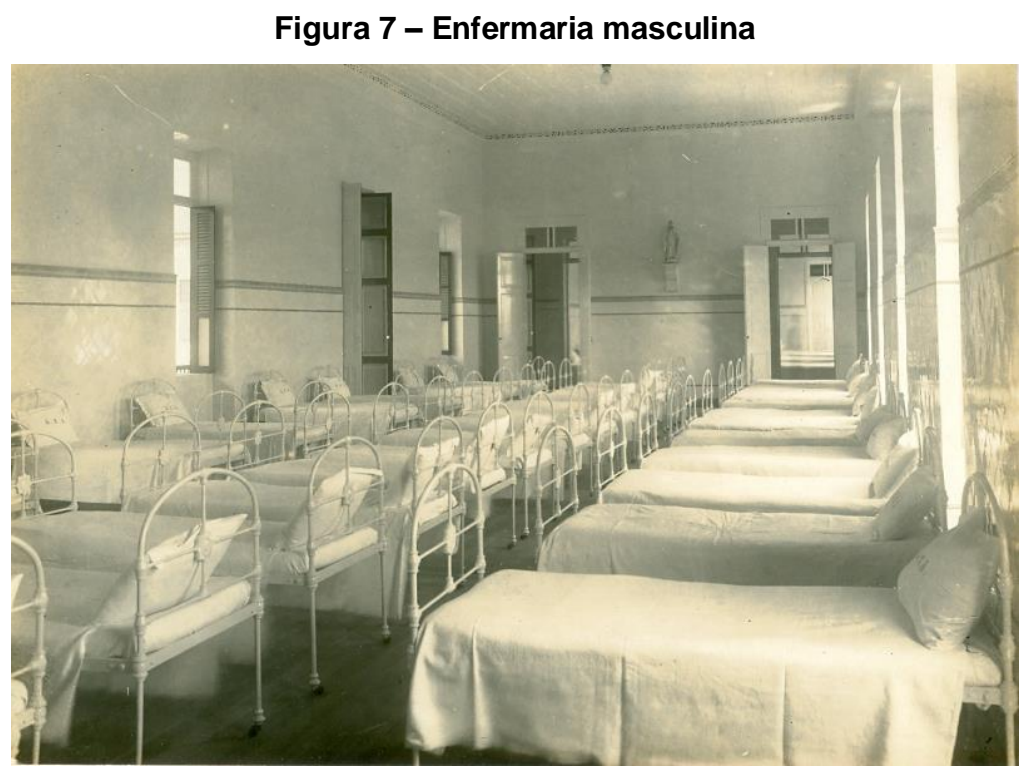

Fonte: Acervo do AFBMP [s.d.]. 
Figura 8 - Refeitório masculino

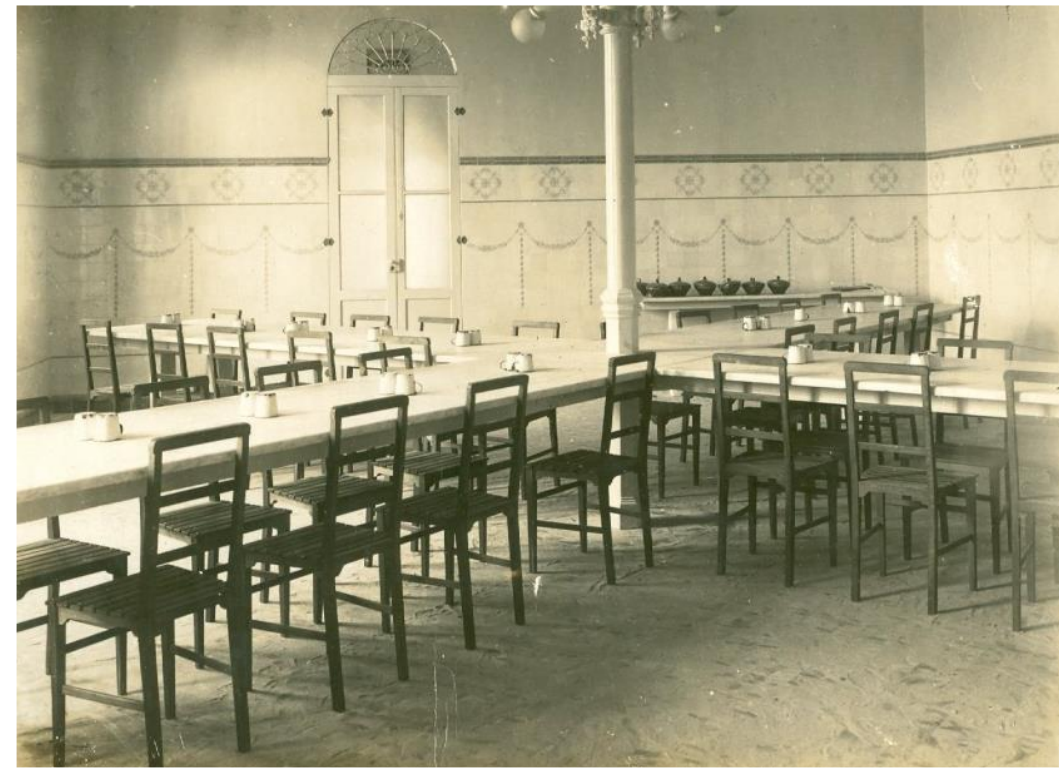

Fonte: Acervo do AFBMP [s.d.].

Figura 9 - Pátio interno com azulejos belgas e calçamento em pedras portuguesas

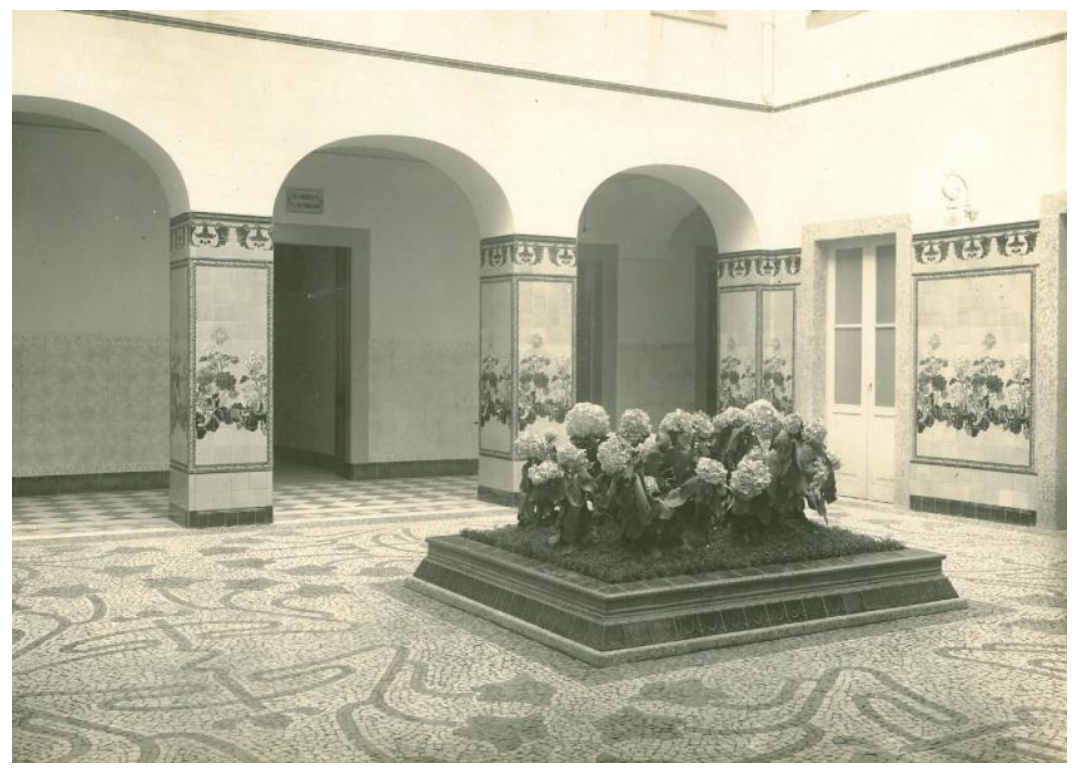

Fonte: Acervo do AFBMP [s.d.]. 
Figura 10 - Sala de Curativo

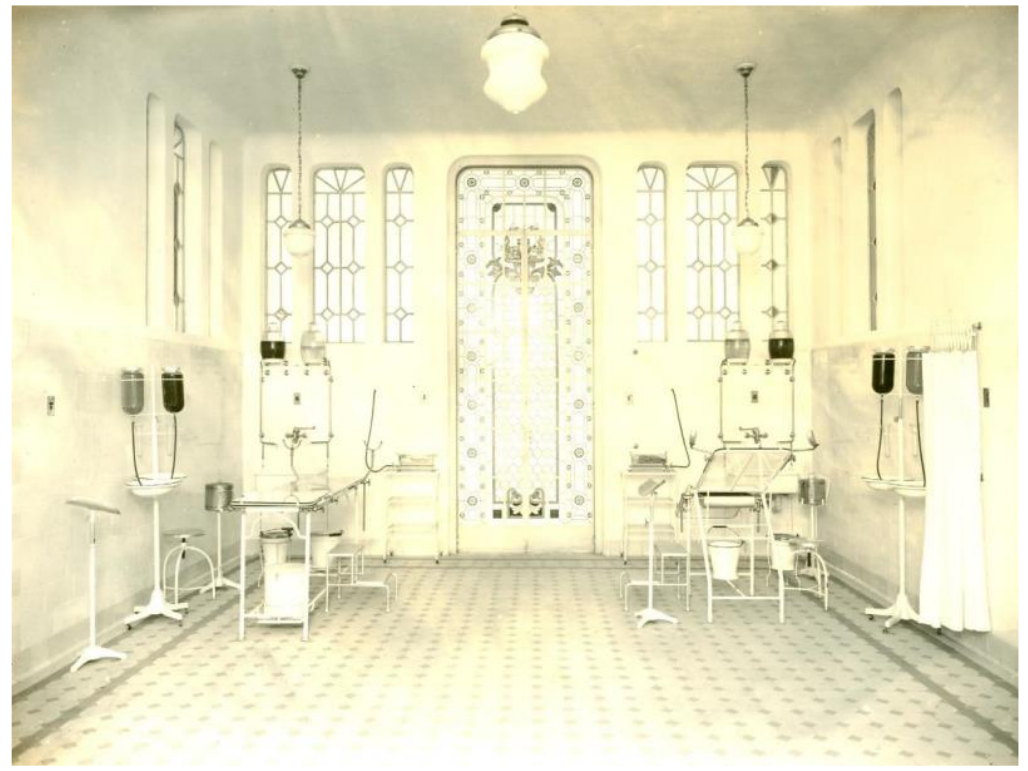

Fonte: Acervo do AFBMP [s.d.].

Figura 11 - Áreas ajardinadas do hospital

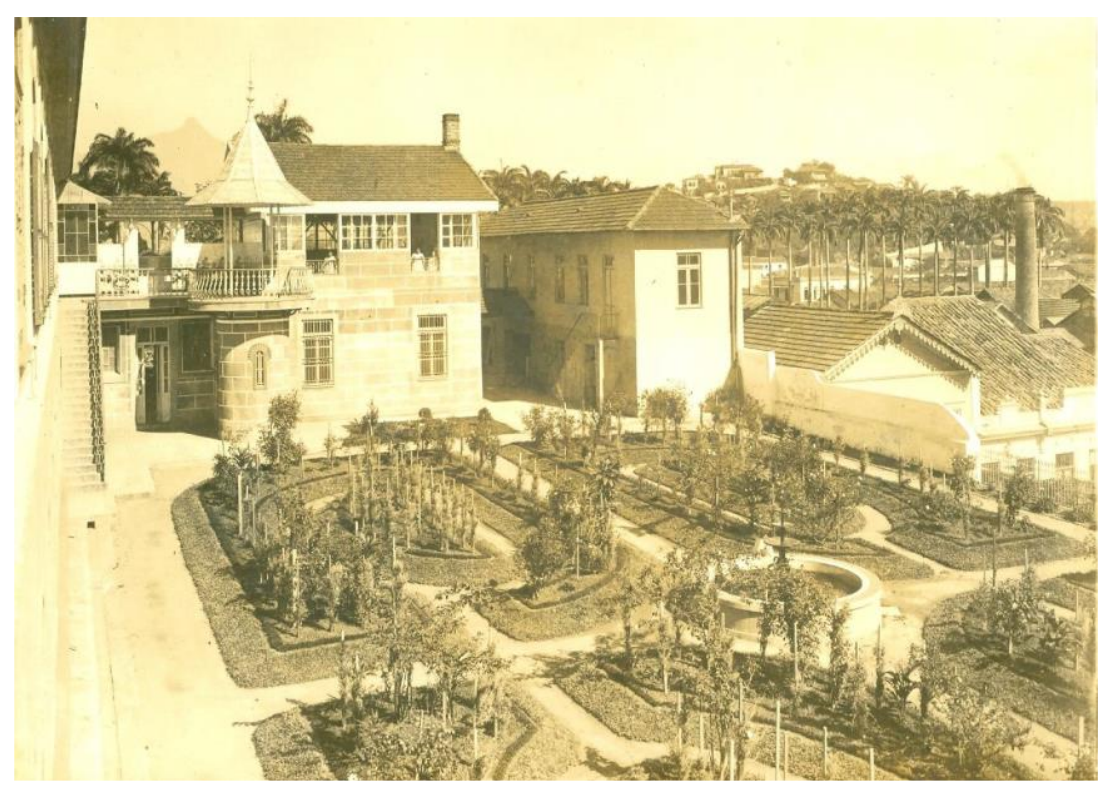

Fonte: Acervo do AFBMP [s.d.]. 


\section{Resultados Finais}

Com esta pesquisa, concluiu-se que o pretexto crucial para o tombamento do Hospital Frei Antônio se relacionava à retórica da perda e ao risco de descaraterização daquela ambiência hospitalar em virtude das obras implementadas em seu entorno naquele período. As funções médico-assistenciais do Lazareto de São Cristóvão, associadas às evidências arquitetônicas de suas instalações, ratificaram sua categorização como patrimônio cultural carioca em 1985.

Durante o século $X X$, as políticas de profilaxia da lepra se desenvolveram no Rio de Janeiro devido à capitalidade política do Município/Distrito Federal, aos debates médicocientíficos em torno do controle da doença e à vasta rede assistencial composta por leprosarias, preventórios, dispensários, entidades filantrópicas, órgãos sanitários, institutos de pesquisa e centros de saúde.

A arquitetura do hospital traduz os desafios em se promover a assistência médica aos portadores de lepra que para lá se encaminhavam. As reformas realizadas no Lazareto propiciaram a terapêutica e o bem-estar dos pacientes e, simultaneamente, corresponderam aos preceitos científico-profiláticos daquela época.

O tombamento do Hospital Frei Antônio foi resultado da conjuntura histórica em que estava inserido e das políticas culturais municipais responsáveis pela patrimonialização de bens arquitetônicos, paisagísticos e artísticos entre 1975 a 1985.

A Prefeitura da Cidade do Rio de Janeiro vivia um processo de reorganização político-administrativa, a partir de 1975, com a fusão dos estados da Guanabara e do Rio de Janeiro. A Secretaria Municipal de Educação e Cultura, o Conselho Municipal de Proteção do Patrimônio Cultural e as divisões de estudo, pesquisa e tombamento se mobilizavam para patrimonializar conjuntos arquitetônicos emblemáticos para a história da cidade. Neste ínterim, além do Hospital Frei Antônio, a Municipalidade promulgou tombamentos de bens, que hoje são classificados como sendo da Saúde: o Hospital da Saúde (1986), o Hospital da Cruz Vermelha (1987), o Hospital da Ordem Terceira de Nossa Senhora do Carmo (1987) e a Casa de Saúde Doutor Eiras (1987).

A salvaguarda do Hospital Frei Antônio se correlaciona com a preservação do bairro de São Cristóvão, com a história da saúde pública no município do Rio de Janeiro e com a ampliação das políticas culturais pelas instâncias governamentais que, nas últimas décadas, 
vêm patrimonializando os acervos arquitetônicos referentes à área da Assistência Médica, da Ciência e da Saúde como patrimônios históricos.

Portanto, esta pesquisa poderá colaborar para a divulgação da documentação administrativa municipal e dos arquivos consultados como fonte de investigação, o incentivo aos diálogos interdisciplinares entre história, memória, patrimônio e saúde, a discussão em relação às políticas públicas de preservação na cidade do Rio de Janeiro e a sensibilização da sociedade diante das propostas de identificação, reconhecimento e valorização do patrimônio histórico local, incluindo os acervos culturais da saúde.

\section{Agradecimentos}

Gostaria de agradecer à Fundação Oswaldo Cruz, à Casa de Oswaldo Cruz, à Coordenação do Mestrado Profissional e aos professores do Programa de Pós-Graduação em Preservação e Gestão do Patrimônio Cultural das Ciências e da Saúde por terem me acolhido e incentivado a continuar pesquisando no campo da História, Memória e Patrimônio Cultural. Um agradecimento especial ao Prof. Dr. Renato da Gama-Rosa Costa por ter sido meu orientador e vir me acompanhando perante os desafios em investigar objetos relacionados à História da Saúde, Arquitetura Hospitalar e Patrimônio Cultural da Saúde.

\section{Referências}

ALECRIM, Laura Karina Nobre. Arquitetura profilática: leprosários brasileiros (19181949). Dissertação (Mestrado) - Programa de Pós-Graduação em Desenvolvimento Urbano, Universidade Federal de Pernambuco, Recife, 2012.

BASTOS, Tarcísio Pereira Bastos. "Aqui renasce a esperança": o tombamento do Hospital Frei Antônio (1976-1985). Dissertação (Mestrado) - Programa de Pós-Graduação em Preservação e Gestão do Patrimônio Cultural das Ciências e da Saúde, Casa de Oswaldo Cruz, Fundação Oswaldo Cruz, Rio de Janeiro, 2018.

CABRAL, Dilma. Lepra, Medicina e Políticas de Saúde no Brasil (1894-1934). Rio de Janeiro: Editora FIOCRUZ, 2013. 
CHUVA, Márcia Regina Romeiro. Os arquitetos da memória: sociogênese das práticas de preservação do patrimônio cultural no Brasil (anos 1930 - 1940). Rio de Janeiro: Editora UFRJ, 2009.

COSTA, Ana Paula Silva da. Asilos Colônias Paulistas: análise de um modelo espacial de confinamento. Dissertação (Mestrado) - Programa de Pós-Graduação em Arquitetura e Urbanismo, Escola de Engenharia de São Carlos, Universidade de São Paulo, São Carlos, 2008a.

COSTA, Renato Gama-Rosa. Arquitetura e Saúde no Rio de Janeiro. In: PORTO, Ângela et al. História da Saúde no Rio de Janeiro: instituições e patrimônio arquitetônico (18081958). Rio de Janeiro: Editora Fiocruz, 2008b.

FONSECA, Maria Cecília Londres. O patrimônio em processo: trajetória da política federal de preservação no Brasil. 2. ed. rev. ampl. Rio de Janeiro: Editora UFRJ; Minc Iphan, 2005.

GONÇALVES, José Reginaldo Santos. A retórica da perda: os discursos do patrimônio cultural no Brasil. Rio de Janeiro: Editora UFRJ; Iphan, 2002.

MONTEIRO, Flávia de Azevedo. O Patrimônio Arquitetônico da Saúde: discussões sobre a história da arquitetura hospitalar do século XIX. Dissertação (Mestrado) Centro de Artes, Universidade Federal do Espírito Santo, Vitória, 2014.

MIURA, Priscila, Miyuki. Quadrilátero da Saúde: espaço de ensino, pesquisa e saúde pública em São Paulo. Dissertação (Mestrado) - Faculdade de Arquitetura e Urbanismo, Universidade de São Paulo, São Paulo, 2012.

RABELLO, Sonia. O Estado na preservação de bens culturais: o tombamento. Rio de Janeiro: IPHAN, 2009.

SANGLARD, Gisele; COSTA, Renato da Gama-Rosa. Memória, História e Patrimônio Cultural da Saúde: uma história possível. In: PORTO, Ângela et al. História da Saúde no Rio de Janeiro: instituições e patrimônio arquitetônico (1808-1958). Rio de Janeiro: Ed. FIOCRUZ, 2008.

SANTOS, Márcia Elizabeth Pinheiro dos. Hospital São Cristóvão dos Lázaros: entre os muros da exclusão. Dissertação (Mestrado) - Programa de Pós-Graduação em Arquitetura e Urbanismo, Faculdade de Arquitetura, Universidade Federal da Bahia, Salvador, 2005.

SERRES, Juliane Conceição Primon. Preservação do Patrimônio Cultural da Saúde no Brasil: uma questão emergente. História, Ciências, Saúde - Manguinhos, Rio de Janeiro, v.22, n.4, out.-dez. 2015.

SERRES, Juliane Primon; BORGES, Viviane Trindade. Leprosários ao sul do Brasil: de locais de sofrimento a lugares de memória. Revista Acervos, Rio de Janeiro, v. 28, n. 2, p. 252-263, jul./dez. 2015, p. 252-263. 